\title{
Usos y sentidos del concepto de democracia en Uruguay (1958-1989)
}

Este trabajo representa una aproximación a los usos y sentidos del concepto de democracia en el Uruguay, entre 1958 y 1989.' Teniendo en cuenta la amplitud cronológica del período abarcado, se priorizará un abordaje panorámico, buscando identificar discursos y prácticas que circularon en los campos político y cultural y que se disputaron el sentido de la democracia. En esta línea, mi trabajo no procurará trazar una definición precisa del concepto y analizar el comportamiento de los actores a luz de ella, sino identificar cuáles fueron las definiciones que los actores asumieron como propias, qué factores políticos y sociales incidieron en esas construcciones, cómo esas construcciones se relacionaron entre sí y cuáles fueron sus trayectorias a lo largo del período. ${ }^{2}$

\section{La crítica a la democracia uruguaya. Entre la cáscara hueca y el monstruo fascista}

En mayo de 1971 el diputado del Partido Colorado Juan Carlos Fa Robaina recibió una carta de un correligionario salteño. En ella se detallaban las actividades que este corresponsal estaba llevando a cabo con el fin de que, tras las elecciones nacionales que se realizarían algunos meses después, el diputado conservara la banca: "También le diré que estamos trabajando fuerte y ya contamos con cincuenta votos que son seguros por tratarse de personas serias y que no usan del engaño; por lo tanto, para las Elecciones podremos contar con quinientos".

Habiendo exhibido sus méritos, a continuación —aplicando una sencilla lógica de intercambio — el corresponsal pidió lo que le correspondía:

Le dire que mi Sra ... perteneció al partido ... pero no podemos seguir donde existe el engaño la mentira y la mala voluntad y lo que digo lo compruebo. / Yo pienso radicarme en Brasil pero si ... me consigue lo que pido me quedaré en Uruguay. [...] Cada uno busca su conveniencia; de mi Patria y mi familia no me olvidaré. Momentos muy amargos [h]emos

* Centro de Fotografia de Montevideo.

1 El trabajo fue realizado en el marco de mi participación en el proyecto Disputas culturales, sociales e ideológicas en el Uruguay de la crisis y el autoritarismo (1955-1985). Elaboración de un diccionario de términos y conceptos históricos. Grupo de Estudios Interdisciplinarios sobre el Pasado Reciente (GEIPAR) Programa CSIC, dirigido por Aldo Marchesi y Vania Markarian.

2 Varios trabajos pueden mencionarse como guías teóricas de este enfoque: Pierre Rosanvallon, Por una historia conceptual de lo político. Lección inaugural en el Collège de France, Buenos Aires, FCE, 2003; Reinhart Koselleck, "Historia conceptual e historia social", en Futuro pasado. Barcelona, Paidós, 1993, Javier Fernández Sebastián (ed.), Political Concepts and Time, Santander, Cantabria University Press, 2011; Inés Cuadro Cawen, "Variaciones del concepto político 'democracia' en el territorio de la Banda Oriental del Uruguay (1770-1870)" en Gerardo Caetano (coord.), Historia conceptual. Voces y conceptos de la política oriental (1750-1870), Montevideo, Banda Orienal, 2013; Gerardo Caetano, "La reconceptualización política de la voz 'democracia' en Iberoamérica antes y después de las independencias", en Crítica Contemporánea. Revista de Teoría Politica, $n^{\circ}$ 1, nov. 2011, pp. 93-114; Mauricio Bruno, "El lenguaje de la revolución. Los textos de agitación política en la revolución oriental (1811-1820)", Montevideo, Colección Avances de Investigación, Departamento de Publicaciones de la Facultad de Humanidades y Ciencias de la Educación, 2010; Gabriel Vommaro, Andreína Adelstein (coords), Diccionario del léxico corriente de la política argentina. Palabras en democracia (1983-2013), Buenos Aires, Editorial UNGS, 2013. 
pasado y no se puede seguir así. Un hombre sin ambición es un barco sin timón. Yo no exijo el oro y el moro como dice el refrán, quiero trabajar y ser útil a mi Patria. No puedo vivir estancado ni tampoco engañado. Otra cosa debo aclararle no quiero interpreten que quieramos [sic] cambiar votos por empleo público. De ninguna manera! Lo que queremos es que la Patria siga siendo democrática. ${ }^{3}$

La apelación final puede interpretarse de dos maneras: por un lado, querer que la patria siguiera siendo "democrática" podría significar que el Partido Colorado triunfara en las elecciones y, de esa manera, evitara el ascenso del "totalitarismo", la "subversión", el "comunismo" antónimos de la palabra democracia en la lógica de las derechas de ambos partidos tradicionales y que, en ese contexto, identificaban con el Frente Amplio (FA) y el Movimiento de Liberación Nacional-Tupamaros (MLN-T). Pero también podía significar algo más sencillo: reivindicar esa patria democrática era querer que se respetaran los pactos, pretender que el caudillo político fuera justo con sus seguidores y premiara sus esfuerzos, aspirar a que un acuerdo más o menos tácito entre privados, mediado por el Estado, no fuera traicionado.

Esta idea se basaba en la confianza en un Estado benefactor - tanto por sus leyes sociales como por sus procedimientos clientelísticos - que entró en crisis a fines de la década del cincuenta y se derrumbó durante los años sesenta, lo cual se evidenció, por un lado, en las crecientes dificultades de los caudillos políticos para hacer frente a este tipo de demandas ${ }^{4}$ y, por otro, en la cristalización de un discurso, nacido entre los intelectuales pero que permeó rápidamente en la política, fuertemente crítico de una democracia uruguaya, pese a verse a sí misma como una panacea de organización social. ${ }^{5}$

Los campos privilegiados para esta crítica fueron la literatura y ensayo, produciendo en varios casos "éxitos de librería y de opinión" ${ }^{\prime 6}$ que reflejaron la avidez del público por una mirada revulsiva de ciertos sentidos comunes sobre la idiosincrasia nacional. Uno de los mejores ejemplos de esta literatura es El país de la cola de paja, del escritor Mario Benedetti, que trazó una crítica moral "por izquierda" a la democracia uruguaya. En ese texto la relacionó con una serie de sentidos por demás ilustrativa: "antifaz de la canalla", "corrupción", búsqueda frenética del confort material y queja insustancial de una ciudadanía apolítica. Para Benedetti, había un:

desequilibrio entre esto que somos y eso otro que pretendemos ser; la gente llega y se divierte bastante, incluso siente un poco de piedad, y en el mejor de los casos algo de estupor. Porque cuando nos ponemos de pie y pronunciamos con alegre desenfado la palabra Democracia, sólo conseguimos parecernos al señor distraído que concurre a una fiesta de rigurosa etiqueta, pero olvida ponerse los pantalones. [Los uruguayos están cegados por el] valor simplemente teórico de la palabra democracia [...] término tan zarandeado en los tiempos modernos [y que en Uruguay no es más que] una maravillosa red de apariencias [...] un refugio de venales, de arribistas, de hipócritas. ${ }^{8}$

La solución a esto no pasaba por la política, sino por la moral. En 1960 Benedetti no le pedía al uruguayo "una sangrienta revolución", pero sí "una revolución de la conciencia [...] asumir la actitud que dicte la conciencia y, luego de aclarada, de reconocida, comprometerse en ella". Tres años después, durante una conferencia en la sede del Partido Socialista, tras el fracaso electoral de la Unión Popular, ${ }^{9}$ su desencanto se había profundizado y, ahora sí, pedía soluciones políticas. La

3 Juan Carlos Fa Robaina, Cartas a un diputado, Montevideo, Editorial Alfa S. A., 1972, pp. 84-85.

$4 \quad$ El libro de Fa Robaina abunda en transcripciones de cartas de votantes decepcionados ante el incumplimiento de sus pedidos. En 1964 un correligionario colorado se declaraba burlado por "los compañeros dirigentes" al negársele un trabajo en el establecimiento "El Espinillar" y señalaba que la "Política lleva nombre femenino y perdone la expresión es puta". En 1968 otro se decepcionaba de que los correligionarios, "después que nosotros luchamos por ellos se van acomodado y a nosotros no dejan aquí pasando de todo un poco" y, uno más, en 1971, afirmaba que los políticos eran todos "cuentistas, falsos, mentirosos [...] cuánto más tienen más quieren, pero no se preocupan por la humanidad" y que Fa Robaina en particular no iba a llegar muy lejos si de esa manera pretendía "conquistar la simpatía de la democracia". Ibíd., pp. 20-21, 47, 129-130.

5 Ver: Luis Batlle Berres. Pensamiento y acción (discursos y artículos). Selección y notas por Santiago Rompani, Tomo I, Montevideo, Editorial Alfa, 1965, pp. 500-501, 510-511, 512.

6 Así calificó Carlos Real de Azúa, en 1964, Crónica General del Uruguay (1958) de Luis Pedro Bonavita, un periodista y político del Partido Nacional Independiente que a comienzos de los años sesenta se acercó a la izquierda comunista y participó activamente de la fundación del Frente Izquierda de Liberación (FIDEL). Carlos Real de Azúa, Antología del ensayo uruguayo contemporáneo, Tomo II. Departamento de Publicaciones de la Universidad de la República, Montevideo, Uruguay, 1964, pp. 359-362. Versión on line en: http://www.archivodeprensa.edu. uy/biblioteca/carlos_real_de_azua/textos/bibliografia/luispedrobonavita.pdf [Acceso: 15 de enero de 2014].

7 Mario Benedetti, El país de la cola de paja, Montevideo, ARCA, 1963 [1ª edición, 1960].

8 lbíd., p. 101.

9 En 1962 el Partido Socialista se presentó a las elecciones aliado al sector nacioalista de Enrique Erro, bajo el lema Unión Popular. La experiencia consechó menos de treinta mil votos y los socialistas no obtuvieron ningún representante parlamentario. 
izquierda debía decidirse, no podía seguir jugando "la carta de la Revolución dentro de un planteo electorero, ni [...] la carta de la democracia representativa dentro de un planteo revolucionario". 10

Otro ejemplo de este sentido común fue la novela El Paredón, de Carlos Martínez Moreno, que trazó un paralelismo entre el "quietismo" de la sociedad uruguaya y la removedora experiencia de la Revolución Cubana a través de la peripecia de su protagonista, Julio Calodoro. El texto incluía una imagen muy gráfica del desprecio por las manifestaciones populares que no se canalizaban por la izquierda política. El personaje principal de la novela veía resignado a la multitud que durante la campaña electoral de 1958 "se contoneaba y aullaba, comía, bebía y deliraba" al son de la demagogia de los partidos; que luego del triunfo de los blancos se agitaba "como en un parque de diversiones, lejos por igual del peligro, de la salvación y de la muerte"; que no tenía sentido alguno de la trascendencia, "tan hecho a la calma, a la llaneza de su destino sin accidentes ni sobresaltos, a la absurda idea de su superioridad"."

Tanto en Martínez Moreno como en Benedetti se notaba, a grandes rasgos, una doble dimensión de la palabra democracia. Por un lado, una que refería a una realidad instituida mediante rituales huecos y discursos presuntuosos que, además, tenía perversos efectos anestesiantes sobre la sociedad, una máscara que tapaba una realidad injusta, inmoral e intolerable. Por otro, una aspiración, una práctica, una esencia democrática, cuyos rasgos palpables no podían definir con palabras pero que intuían en su definición etimológica. No estaba claro qué era para ellos el gobierno del pueblo pero sí lo estaba que no era aquello que tenía el Uruguay. Y cuando Martínez Moreno se preguntara, en esa coyuntura: "¿qué es democracia, la aspiración a una sociedad más justa o la funda del desabrido institucionalismo sin contenido real de justicia?", encontraría la respuesta en Cuba. Allí se estaba resolviendo satisfactoriamente cierta contradicción entre forma y contenido. Pues, "para realizar revolucionariamente un programa democrático hay que dejar de lado la mecánica del juego político connatural a la democracia ya asentada. Si no, este juego se lleva aquellos objetivos". ${ }^{2}$

Los comunistas no secundaron este discurso híper crítico. De todas formas - y si bien a partir de 1955 llevaron a cabo una línea de reflexión en torno al concepto de democracia, en el marco de su política de alianzas con otros partidos políticos y movimientos sociales, y buscaron incorporarla a varias de sus formulaciones políticas - ${ }^{13}$ en líneas generales resistieron definirse como una fuerza "democrática", por un razón muy sencilla: la apropiación que las derechas de los partidos tradicionales habían hecho del concepto y su resignificación como sinónimo de anticomunismo.14

La victoria del Partido Nacional en las elecciones de 1958 — más precisamente de la alianza herrero-ruralista— significó la entronización en el gobierno de una nueva concepción de la democracia. Para gran parte del nuevo elenco gobernante la democracia era todo aquello que no era comunismo. Así, lejos de enfatizar en los derechos individuales, el gobierno electo mediante elecciones libres, las libertades sindicales y de opinión, el diario del líder ruralista Benito Nardone sugería que los "uruguayos demócratas y patriotas" debían llevar al paredón "a los israelitas rojos" de un centro cultural cercano al Partido Comunista; una asociación "democrática" de Rivera proponía hacer una "lista negra" con los nombres de todos los militantes de los "partidos antidemocráticos y antinacionales, bregando para que nadie mantenga relaciones comerciales, culturales o amistosas" con ellos, pidiendo además al gobierno más dureza con el comunismo y amenazándolo con "pasar por alto a las autoridades establecidas". El propio Nardone se quejaba amargamente de las "amplísimas garantías del derecho democrático" que había en Uruguay. El mundo estaba en medio de una guerra entre la democracia y el comunismo. Por eso, para el diario colorado El Día - activo propulsor de esta campaña anticomunista—, cuando un grupo de manifestantes anticomunistas concurrió armado a la sede del Partido Comunista, provocando un enfrentamiento en que moriría uno de los manifestantes, este sería recordado como un entrañable "ciudadano demócrata". 15

10 Mario Benedetti, op. cit., p. 143.

11 Carlos Martínez Moreno, El Paredón, Barcelona, Seix Barral, 1963, pp. 8-9.

12 Carlos Martínez Moreno, en: Carlos Real de Azúa, Antología del ensayo uruguayo contemporáneo, op. cit., p. 485, citado por Hebert Gatto, El cielo por asalto. El movimiento de liberación nacional (Tupamaros) y la izquierda uruguaya (1963-1972), Montevideo, Taurus, 2004, p. 109.

13 En diferentes documentos partidarios, congresos y editoriales, tanto Arismendi como otros dirigentes relevantes del Partido Comunista hablaron de movimiento, frente república y gobierno "democrático popular". Ver: Gerardo Leibner, Camaradas y compañeros. Una historia política y social de los comunistas del Uruguay, Montevideo, Ediciones Trilce, 2011, p. 238-239.

14 Ver: Magdalena Broqueas, La trama autoritaria. Derechas y violencia en Uruguay. 1958-1966, Montevideo,Banda Oriental, 2014.

15 "Ojo al palo...", en Diario Rural, 15 de mayo de 1961, p. 3; "Contra el régimen de Cuba", en Diario Rural, 26 de febrero de 1962, p. $12 ;$ "A la opinión pública del país", en Diario Rural, 10 de octubre de 1960, p. 16; ",La tierra tiene que ser de quien la trabaja'. Estructura nueva sobre la base de un viejo principio en nuestras modalidades de lucha", en Diario Rural, 23 de mayo de 1960, p. 2, 9; Benito Nardone, Peligro Rojo en América Latina, Montevideo, Impresiones Diario Rural S. A., 1961, p. 9; "Defendamos la democracia", en El Día, 13 de enero de 1961, p. 9; "Millares de 
Con el gobierno herrero-ruralista, el concepto democracia adquirió otra connotación negativa para la izquierda. Si el Uruguay democrático de la tradición batllista era un cadáver prolijamente amortajado, el que inauguraba Benito Nardone era, además, un activo monstruo "fascista". 16

\section{La democracia entre la falsa conciencia y la guerra antisubversiva}

A fines de los sesenta el discurso crítico sobre la democracia uruguaya ya no ocupaba el lugar marginal que una década atrás le había adjudicado el pesimista diagnóstico de Benedetti. La sociedad estaba movilizada y consumía con avidez la producción de los intelectuales que estaban pensando el país. El fascículo de la popular Enciclopedia Uruguaya dedicado a la "democracia política", escrito por Germán Rama, expresaba claramente este clima de época. Rama destacaba que Uruguay asistía, durante las últimas cinco décadas, a "un funcionamiento relativamente regular de la democracia", debido a factores de integración como la alta participación electoral, el predominio de los partidos tradicionales, su escaso crecimiento poblacional, la estabilidad de la institución familiar, la educación, el consumo, la seguridad social y la movilidad social. Sin embargo, lejos de concebir a estos factores como "positivos de por sí", terminaba su trabajo con una hipótesis paradójica: "puede postularse que la crisis actual de la sociedad nacional proviene justamente de la existencia de mecanismos de integración que han evitado o canalizado los auténticos conflictos sociales, previos a la realización de una sociedad auténticamente igualitaria y libre".17

Por su puesto que este descrédito de la democracia no era una peculiaridad local. Mafalda, el personaje de Quino que describía irónicamente la realidad argentina y que ya circulaba en Uruguay en esa época, reía desde la mañana a la noche al leer en un diccionario que democracia significaba "gobierno en que el pueblo ejerce la soberanía" y veía a los "ideales democráticos" como una nube desvaneciéndose. ${ }^{18}$

Los defensores de la democracia apelaron al rescate de las prácticas más cuestionadas por el discurso crítico. El diputado Juan Carlos Fa Robaina —en el libro que más arriba comentáramos_ reivindicó al "favor político o más genéricamente la rioplantense 'gauchada"', señalando que no era una peculiaridad uruguaya, sino que existía en todas las democracias y que era una forma válida de contacto entre el pueblo y los políticos, al tiempo que el dirigente batllista Luis Hierro Gambardella, prologando, defendió esas prácticas como un mecanismo necesario de integración social en el contexto de una economía en retroceso. ${ }^{19}$

Los decretos de Medidas Prontas de Seguridad y de congelación de precios y salarios, de junio de 1968, mostraron los límites del imaginario batllista. ${ }^{20}$ La movilización social se radicalizó y la represión se endureció. Hacia fines de año, el presidente Pacheco Areco comenzó a hablar de una "democracia amenazada", cuya salvación aparecía como el gran objetivo de su gobierno. La dicotomía orden-subversión se planteó como el eje de la política y la democracia, tal como había sucedido

personas reunidas ayer en Plaza Independencia repudiaron al castrismo vivando la libertad y la democracia”, en El Día, 12 de enero de 1961, p. 16

El diputado socialista Germán D'elía lo diría claramente en 1962: "frente a las medidas represivas queda siempre el camino de la revolución para llevar al pueblo al poder. Y que luego [...] no se derramen lágrimas de cocodrilo hablando de la democracia y protestando contra las medidas de un gobierno revolucionario" (Diario de sesiones de la cámara de representantes, 31 de julio de 1962, p. 124).

17 Germán Rama, "La democracia política", en Enciclopedia Uruguaya, n 44, Montevideo, Arca, agosto de 1969, pp. 62-78. Este planteo parece una forma más sutil del que animaba la movilización del MLN-T, según el cual la "democracia representativa, régimen 'legal', y gobierno electo" del Uruguay ocultaban "la explotación, la violencia y la dictadura de clases". (Movimiento de Liberación Nacional, Documento n 1, junio de 1967 Disponible en http://www.archivochile.com/America_latina/JCR/MLN_T/tupa_de/tupade0001.pdf [Acceso: 27 de noviembre de 2013].)

18 Un compilado de viñetas de Mafalfa con énfasis en la sátira política puede consultarse en: http://www.unitedexplanations.org/2013/06/18/ las-35-mejores-vinetas-de-mafalda-de-satira-politica/. Ver, además: Isabella Cosse, Mafalda. Historia social y política. Buenos Aires, Fondo de Cultura Económica, 2014

19 Juan Carlos Fa Robaina, op. cit., pp. 10, 14.

20 En el discuso de Jorge Pacheco Áreco, previo a esa fecha, pueden encontrarse apelaciones al imaginario battlista, por ejemplo, al "perfil democrático inquebrantable que honra al País", caracterizado por "los notables logros de la educación popular y la cultura, y el arraigado y pleno ejercicio de la democracia política y social" "'Discurso del señor Presidente de la República, Don Jorge Pacheco Areco pronunciado en la ciudad de Paysandú el $1^{\circ}$ de marzo de 1968. 'Compromiso de Paysandúm, en: Jorge Pacheco Areco, Discursos, mensajes y declaraciones del señor Presidente de la República Oriental del Uruguay Don Jorge Pacheco Areco, Montevideo, Presidencia de la República, 1968, pp. 20-37). 
en Nardone, se volcó al polo del orden. Como diría una semana antes de las elecciones de noviembre de 1971, de un lado estaban los "enemigos de la República" y, del otro "los defensores del país", de un lado la "sedición y el crimen", del otro, "la democracia, la paz y la libertad".21

La democracia para Pacheco — al igual que para Nardone- era un concepto más vinculado a la guerra que a la política. Era aquello que la subversión buscaba destruir y eso era "un sistema, un estilo de vida, en nuestro caso, el modo de ser uruguayo". No se trataba de defender la organización política que la comunidad se había dado. Incluso el Parlamento, factor clave de esa organización, estaba frecuentemente del lado de afuera de su discurso, del lado del ellos, como las "amplísimas garantías de la democracia" estaban por fuera del de Nardone. Lo que se defendía era la vida misma de esa comunidad, sus costumbres, tradiciones, todo aquello que se suponía previo a la política y que no entraba en el orden de lo discutible. Por eso el Pacheco que buscaba la reelección en 1971 — como ha señalado Francisco Panizza — ya no le hablaba a los "ciudadanos" - concepto de identidad política - como en sus primeras apariciones públicas. Le hablaba a los "hombres y mujeres del Uruguay" que veían amenazada "la paz de [sus] hogares" — concepto de identidad social, la familia — "por medio de la violencia o la corrupción". Y no se definía como "un político en el sentido que se entiende habitualmente", sino como un "hombre que lucha denodadamente contra todo lo que no sea el interés nacional".22

Durante la mañana del 14 de abril de 1972 los Tupamaros asesinaron al profesor Armando Acosta y Lara, a los policías Oscar Delega y Juan Carlos Leytes y al capitán de corbeta Ernesto Moto, todos acusados de formar parte del Escuadrón de la muerte. Horas más tarde las Fuerzas Conjuntas ejecutaron a ocho miembros del MLN-T. Al día siguiente la Asamblea General aprobó, con excepción de los legisladores del Frente Amplio, la "Suspensión de las garantías individuales" y el "Estado de guerra interno". Durante la sesión, el senador pachequista Raumar Jude pidió que se votara un minuto de silencio por "Acosta y Lara y los caídos en nombre de las instituciones". Los frenteamplistas Rodney Arismedi y Enrique Rodríguez acotaron que el minuto debía ser "por todos los muertos", agregando los nombres de algunas víctimas de la represión policial durante los últimos años, como Líber Arce y Heber Nieto. El nacionalista Wilson Ferreyra Aldunate sostuvo que votaría la moción, "pero hay más muertos [que los señalados por Jude]", mientras el también frenteamplista Daniel Sosa Díaz pidió por el poeta Íbero Gutiérrez, asesinado por el Escuadrón de la muerte. Ante la confusión de qué era lo que se iba a votar, Jude aclaró: "un minuto de silencio por los fallecidos en defensa de la democracia". "Entonces no son todos los caídos", respondió el frenteamplista Enrique Erro, mientras Arismendi pedía que la moción fuera por "los caídos, sin nombres" y Ferreyra Aldunate insistía "por todos los muertos". ${ }^{23}$ La palabra democracia, en boca de un senador pachequista, venía cargada de anticomunismo, de la lógica del ellos subversivos / nosotros democráticos y esto era claro tanto para los frenteamplistas como para Ferreyra Aldunate, que pretendían impedir ese uso. Sin embargo, la moción se puso a votación sin modificaciones y terminó siendo aprobada por unanimidad.

\section{Una dictadura democrática}

Aunque con importantes dificultades, hasta junio de 1973 funcionaron las instituciones parlamentarias. Tal vez eso impida percibir claramente el uso militantemente anticomunista que las derechas de los partidos tradicionales hicieron del concepto de democracia a partir de los primeros años de la década de los sesenta. Es que, por un lado, había Parlamento, elecciones, proclamados derechos individuales y, por el otro, partidos políticos que ocupaban el gobierno y defendían un concepto de democracia. Y una interpretación anacrónica podría hacernos vincular automáticamente ambas cosas y concluir que esas derechas buscaban defender las elecciones, las garantías constitucionales, el Parlamento, todo el andamiaje institucional de la democracia liberal. Pero a partir de junio de 1973, liberado de ese andamiaje, el uso de la democracia como un arma

21 Francisco Panizza, Uruguay: batllismo y después. Pacheco, militares y tupamaros en la crisis del Uruguay batllista, Montevideo, Ediciones de la Banda Oriental, 1990, pp. 126, 137, 139-142. El entrecomillado corresponde a diversas alocuciones públicas de Pacheco, citadas por el autor. 22 lbíd.

23 La transcripción de la discusión puede encontrarse en: Aldo Marchesi, “¿'Guerra' o 'Terrorismo de Estado'? Recuerdos enfrentados sobre el pasado reciente uruguayo", en Elizabeth Jelin (comp.), Las conmemoraciones: las disputas en las fechas "in-felices", Madrid, Siglo XXI, 2002, pp. 144-145. 
anticomunista se percibe claramente. El sueño de Benito Nardone se hace realidad y la democracia logra despojarse de las "amplísimas garantías del derecho democrático". En este sentido, la dictadura uruguaya fue profundamente democrática.

El "estilo de vida" y la "tradición" serían los pilares de esta concepción de la democracia. Si bien se hacía referencia a las "instituciones", éstas no debían confundirse con ningún perimido concepto de una democracia formal y desnaturalizada, [ninguna] demagógica armazón de democracia hueca y pluralista [...] formalista y declamatoria, de pequeños círculos y gastadas figuras profesionales, apartada de los intereses y las necesidades apremiantes de la Nación, [ninguna] democracia liberal anestesiada por politiquería. ${ }^{24}$

¿Quiénes eran el objeto de esa advertencia? Pues los políticos, "fanáticos de la falsa democracia [diría el presidente Aparicio Méndez en setiembre de 1976], los que con tal de mantenerla en el papel y poder invocarla en estado de pureza extraterrena, no se preocupan al verla avasallada o se olvidan que la negaron".25

La meta del gobierno era la "restauración democrática", diría Aparicio Méndez en 1976. La "democracia perfecta", afirmaría el Teniente General Julio César Vadora en 1977. O la construcción de "instituciones genuinamente democráticas", según el Teniente General Gregorio Álvarez un año más tarde. Los partidos "democráticos" —léase los tradicionales más la Unión Cívica - volverían a ocupar su lugar una vez que fueran saneados de la "politiquería". La democracia uruguaya dejaría de ser "equidistante y neutral", adquiriría un compromiso con la esencia de la "nacionalidad oriental" y pasaría a ser "recia, militante, imbuida de sus propios fines y valores". Por ello, "el actual proceso revolucionario institucionalizador [así definía la Junta de Comandantes en Jefe a la dictadura, era] demócrata en toda su raigambre. [...] Si bien ha dejado en suspenso el sistema de la democracia como método [...] permanece vigente en absoluto como doctrina". ${ }^{26}$

Esta visión fue compartida por aquellos civiles que, sin integrar el gobierno, respaldaron su política anticomunista. En abril de 1976 la revista Búsqueda publicó un artículo del periodista argentino Mariano Grondona, cuyo análisis de la realidad de los países del Cono Sur iba en esa línea. Para Grondona los "militares del Cono Sur" tenían motivaciones comunes, entre ellas, la "seguridad, el orden, la administración y el desarrollo", además de la "persistencia del ideal democrático". Su objetivo era "poner las bases, las precondiciones del buen funcionamiento democrático. Sin esas precauciones, la democracia no puede ser tal sino demagogia, la lucha de clases, anarquía". 27

Gran parte de este diagnóstico era compartido por Juan María Bordaberry. Para él, en junio de 1973, Uruguay había terminado con la "vieja democracia liberal [...] formal al estilo clásico [y] hueca", basada en la "filosofía enciclopedista del siglo XVIII", que poco tenía que ver con su realidad. Había terminado con un sistema que atraía al ciudadano a las urnas "por la excitación de sus pasiones, por la promesa, por la dádiva [...] por la propaganda estruendosa o, más recientemente, con la aparición de los partidos radicales de izquierda, hasta por la violencia".

Sin embargo, a diferencia de los militares, Bordaberry no se limitó a la crítica de la democracia liberal ni, tampoco, al mero empleo de los adjetivos que debían caracterizar a la "nueva democracia" — "auténtica", "militante", "sana, virtuosa y eficiente"- ${ }^{28}$ sino que también trazó un esquema bastante acabado de ella.

En una conferencia pronunciada en la Universidad de Chile en 1979 , dedicada a discutir la estructura institucional que debería tener una "democracia protegida", Bordaberry señaló que debería basarse en los "principios cristianos del orden político" y establecer claramente que en la vida "hay verdades permanentes e inmutables, de las que se desprenden derechos esenciales y primarios por cuya vigencia siempre debe velarse". Estos derechos eran la "libertad, el trabajo, la propiedad [...] el orden público y la justicia social" y poco tenían que ver con "la mera forma de gobierno denominada democrática".

24 Junta de Comandantes en Jefe, El proceso político. Las Fuerzas Armadas al pueblo oriental, Montevideo, s.e, 1978, pp. 47, 149-151, 412.

25 Ibíd., p. 395.

26 Ibíd., 1978, pp. 305, 376, 393, 437, 458, 461.

27 "Comunidad de Destinos en el Cono Sur. Por Mariano Grondona", en Búsqueda, abril de 1976, pp. 36-37.

28 El énfasis en la adjetivación - y en esto la tentativa de Bordaberry no difería de la que habían ensayado los comunistas en la década del sesenta- daba cuenta de un ejercicio consciente en pos de reformular el sentido hegemónico de la palabra. Asumía hablar desde un lugar marginal y, desde allí, batallaba. Para Bordaberry, la postura de que la democracia "no admite adjetivos [es la del] puro pensamiento liberal", la de aquel 
En este orden político las FFAA dejarían de ejercer el gobierno, pero velarían por la salud de la nación y serían la "reserva de la soberanía nacional", de la misma forma que las monarquías lo eran en algunos países europeos. Podrían elegir al Presidente o, por lo menos, aprobar los candidatos postulados, guardándose el derecho de someterlos a juicio político en circunstancias de extrema gravedad. ${ }^{29}$

Puesto que ni los militares ni los políticos iban a ejercer la función cotidiana de gobierno, ésta se reservaría a técnicos especializados, surgidos de una Escuela Nacional de Administración especialmente dedicada a ese fin, que formaría "funcionarios públicos competentes y capaces, que dignifiquen y vuelvan a prestigiar la función". Una vez establecido, gracias al "triunfo de las armas", la inmutabilidad de las bases del sistema, lo que quedaba era mejorarlo, perfeccionarlo, pulirlo mediante una eficiente gestión de los asuntos técnicos. Decía Bordaberry en 1976 que, en el futuro, el marxismo estaría excluido de la sociedad, no por una cuestión de represión, sino de mera incompatibilidad: quedaría fuera del orden de lo pensable. Entonces, si la disyuntiva de orden político — qué forma de organización de la comunidad es la más justa- estaba en camino de desaparecer, lo importante era enfocarse en la de orden técnico — cómo podemos hacer más eficaz y eficiente esta organización. Más claro lo diría el propio Bordaberry:

el administrado en las sociedades desarrolladas de hoy quiere ser justamente eso, administrado en su interés general, más que liderado políticamente [...] Hoy se responsabiliza al gobernante tanto por no ser justo como por no haber previsto adecuadamente las fuentes energéticas o disminuido la inflación. ${ }^{30}$

En este marco, la participación de la ciudadanía se limitaría a dos aspectos: por un lado, integración o apoyo a "corrientes de opinión", que podrían proclamar y difundir ideas pero no pretender "el objetivo del poder" —lo cual las diferenciaba de los desaparecidos partidos políticos-y, por otro, "voluntariado", ese sistema "que tiene manifestaciones en muchas partes del mundo" ${ }^{31}$ y que tenía la virtud de proporcionar "una forma de realización personal, en el enfrentamiento y solución de los problemas comunitarios", [contribuyendo] a que el hombre se sienta integrante de una sociedad más justa y aleja[ndolo] así [de] la falacia marxista". ${ }^{32}$

\title{
El consenso socialdemócrata y sus disidencias
}

\begin{abstract}
Allá en mi patria, para luchar contra la dictadura que nos oprimió olvidamos temporalmente la polémica ideológica y nos hicimos el propósito unitario para construir primero el piso firme de una democracia sobre la cual pudiéramos movernos libremente todos los partidos, todas las ideologías, para la controversia ideológica. Allá, comunistas, social-cristianos, socialdemócratas, el movimiento sindical, la empresa privada, las instituciones culturales, nos unimos en una sola voluntad para enfrentar la dictadura..$^{33}$
\end{abstract}

La frase pertenece al ex Presidente venezolano Carlos Andrés Pérez y apareció citada en una compilación de documentos de la Convergencia Democrática en Uruguay (CDU), publicada en 1984. Representa fielmente uno de los sentidos predominantes del concepto de democracia para los sectores opositores a la dictadura en la primera mitad de la década de los ochenta: democracia era todo aquello que se opusiera a la dictadura.

que sabe que su concepto es compartido y que, por eso mismo, no necesita ponerlo en palabras. (Las opciones, Montevideo, Imprenta Rosgal S.A., 1980, pp. 22-31).

29 Junta de Comandantes en Jefe, op. cit., 1978, pp. 351, 359. Juan María Bordaberry, Las opciones, op. cit., pp. 21, 33, 44-48; Juan María Bordaberry, Encuentro Bordaberry - Pinochet. Discurso del Presidente Juan María Bordaberry, Montevideo, Presidencia de la República, 1976, pp. 11-15.

30 Juan María Bordaberry, Las opciones, op. cit., p. 54; Juan María Bordaberry, Encuentro Bordaberry - Pinochet., op. cit. p. 11-15.

31 Especialmente en el Chile de Pinochet, modelo indudable de Bordaberry a la hora de definir su sistema de gestión pública y de participación ciudadana. Ver: Verónica Valdivia Ortiz de Zárate, “'¡Estamos en guerra, señores!' El régimen militar de Pinochet y el pueblo, 1973-1980”, en Historia, $n^{\circ} 43$, Vol. I. Enero-junio de 2010, pp. 163-201. Versión on line en: http://www.scielo.cl/pdf/historia/v43n1/art05.pdf [Acceso: 24 de enero de 2014].

32 Juan María Bordaberry, Las opciones, op. cit., pp. 50-53.

33 Convergencia democrática en Uruguay, Documentos políticos. La CDU una experiencia unitaria, México, Ediciones CDU, 1984 , pp. 14-15. 
Los años de represión dictatorial imprimieron esta mirada incluso en algunos de aquellos intelectuales que habían cuestionado más duramente la realidad de la democracia uruguaya. Ese giro se puede apreciar, por ejemplo, en las posturas de Carlos Martínez Moreno, quien en 1980 firmó una declaración constitutiva de la CDU que celebraba, entre otras cosas, la ejemplar tradición democrática del Uruguay, que lo distinguía del resto de los estados latinoamericanos. ${ }^{34}$

La CDU se apoyaba en un contexto internacional dominado por las ideas liberales en materia política, que trascendían al liberalismo propiamente dicho y encarnaban entre los socialistas y los eurocomunistas. No en vano destacaba el apoyo prestado por las Internacionales Liberal, Socialista y Democrata-cristiana, así como por el Parlamento Europeo y referentes la Democracia Cristiana Italiana, del Partido Socialista Obrero Español y del Partido Comunista de España, como Giulio Andreotti, Felipe González y Santiago Carrillo. En esa línea, democracia eran "los valores supremos de la libertad", en concreto "partidos políticos fuertes, de amplia base popular", libertad de los presos políticos, retorno de los exiliados, garantía de los derechos de reunión y expresión, a lo que agregaban una "distribución más justa de las riquezas" y mayores espacios para la participación de los jóvenes. 35

Este tono social-demócrata de la democracia fue el dominante durante la transición. Entre 1983 y 1984 la revista Guambia realizó una serie de reportajes a figuras de la política uruguaya. Julio María Sanguinetti, Manuel Flores Silva, Fernando Oliú, y Carlos Julio Pereyra coincidieron en señalar que, a la hora de definirse políticamente, la palabra que más los representaba era "social-demócrata". Wilson Ferreira Aldunate decía lo mismo desde Argentina y Líber Seregni evitaba la palabra pero reivindicaba los mismos contenidos que el resto. Esta concepción trascendía a las figuras de los partidos políticos y parecía ser un sentido común de cualquier ciudadano opuesto a la dictadura. El futbolista Fernando Morena afirmaba ser partidario de la social-democracia y que, haber sido español, hubiera votado a Felipe González; "socialismo, sin marxismo", especificaba. Mientras que el músico Ruben Rada sostenía que "no hay socialismo sin democracia y no hay democracia sin socialismo" . ${ }^{6}$

La democracia, para ser tal, debía apoyarse en un campo político y social que reuniera los siguientes atributos: coherencia, sensatez, moderación y racionalidad. Debía ser estrictamente liberal en lo político y, en lo económico, estatista, nacionalista o socialista (según los matices), aunque alejándose siempre del marxismo. Julio María Sanguinetti — tal vez el mayor exponente de este modelo_ lo diría al destacar las similitudes del batllismo con el radicalismo argentino: "sólida tradición democrática por un lado y [...] nacionalismo económico por el otro". ${ }^{37}$

Cabe destacar, además, las similitudes de este modelo con el propuesto por las Ciencias Sociales —en especial la Ciencia Política - en el contexto de la transición, uno de cuyos principales ejemplos es el libro Democracia a la uruguaya, del sociólogo Rolando Franco. Allí se analizaba el comportamiento electoral de los uruguayos en clave histórica y se destacaba la "gran confluencia en el centro del espectro político" que habían significado las elecciones de 1984. El libro fue prologado

por el presidente Sanguinetti, que saludó en él la llegada de un libro "de orientación científica", de una "descripción fáctica objetiva y [un] análisis interpretativo metodológicamente riguroso" de la política uruguaya. ${ }^{38}$

34 "Declaración constitutiva de la Convergencia Democrática en Uruguay", firmada por Diego Achard, Juan Raúl Ferreira, Carlos Martínez Moreno, Luís Echave, Carlos Gurméndez, Juan Eyherachar, Atilio Scarpa, José Korzeniak, Justino Zavala, en Ibíd., p. 17.

35 Ibíd. pp. 28, 53.

36 "Reportajes sin corbata. Julio María Sanguinetti", en Guambia. Expresión uruguaya de humor, año I, n², junio de 1983, pp. 12-13; "Reportajes sin corbata. Manuel Flores Silva", en Guambia. Expresión uruguaya de humor, año I, n 10, [noviembre - diciembre] de 1983, p. 12; "Reportajes sin corbata. Fernando Oliú", en Guambia. Expresión uruguaya de humor, año l, n 3, julio de 1983, p. 13; "Reportajes sin corbata. Carlos Julio Pereyra", en Guambia. Expresión uruguaya de humor, año I, n 15, [marzo] de 1984, p. 33; "Reportajes sin corbata. Líber Seregni", Guambia. Expresión uruguaya de humor, año I, n 17, [marzo-abril] de 1984, p. 34; "Reportajes sin corbata. Fernando Morena", Guambia. Expresión uruguaya de humor, año I, n 5, agosto de 1983, p. 12. "Reportajes sin corbata. Ruben Rada", en Guambia. Expresión uruguaya de humor, año I, $n^{\circ}$ 8, octubre de 1983, p. 10. Arturo Ardao, "Wilson Ferreria y la democracia social", Cuadernos de Marcha, $n^{\circ} 137$, marzo de $1998, \mathrm{p} .31$. Versión digital en http://www.autoresdeluruguay.uy/biblioteca/arturo_ardao/docs/marcha/Wilson_Ferreira.pdf [Acceso: 10 de enero de 2014].

37 Reportaje a Julio María Sanguinetti de la revista argentina Somos, 24 de agosto de 1984. Citado en: Marcelo Pereira, 1980-1984. Operación Sanguinetti, Montevideo, Centro Uruguay Independiente, $2^{\text {a }}$ edición, julio de 1986. La construcción discursiva de este modelo de democracia por parte de Sanguinetti está trabajada en Álvaro de Giorgi, Sanguinetti. La otra historia del pasado reciente, Montevideo, Fin de Siglo, 2014.

38 Con respecto al modelo de democracia propuesto por las Ciencias Sociales durante la segunda mitad de la década de 1980, además del libro de Franco (Rolando Franco, Democracia 'a la uruguaya'. Análisis electoral 1925-1985, Montevideo, El Libro Libre, noviembre de 1985, pp. 7-10 [1ª edición noviembre de 1984]), pueden señalarse los trabajos de Gerardo Caetano, Jose Rilla, Romeo Pérez ("La partidocracia uruguaya. Historia y teoría de la centralidad de los partidos", en Cuadernos del Claeh, vol. 44, 1987, pp. 39-61); Germán Rama (La democracia en Uruguay. Una perspectiva de interpretación, Montevideo, ARCA, 1989, p. 13 [1ª ed. Buenos Aires, Grupo Editor Latinoamericano, 1987]); Aldo Solari ("Algu- 
Claro que había desviaciones del canon social-demócrata, como la de Jorge Batlle, quién interrogado acerca de qué había que cambiar en Uruguay respondía: "Y la democracia". Esto implicaba modificar el rol del Estado, al que definía como un "esqueleto, un protoplasma informe [que] se ha transformado en una pesada lápida, en un protoplasma que está acogotado y que hay que mantener y que funciona mal. ¡Qué me vienen a contar que afecta la soberanía vender los teléfonos! Lo que pasa es que nadie quiere comprarlos". ${ }^{39}$

Una postura similar puede encontrarse en el semanario Búsqueda, que en los meses previos a las elecciones de 1984 se ocupó de pregonar las ventajas de la liberalización y de las gestión técnica y científica de la economía, al tiempo que advirtió de los riesgos de las propuestas "demagógicas" que, desde todos los partidos, reclaman el regreso de una dirección política de la economía. ${ }^{40}$

Otra desviación de ese canon, aunque por izquierda, fue la de los comunistas. Su secretario general, Rodney Arismedi, revindicaba un concepto de "democracia avanzada" y aclaraba que, si bien el Frente Amplio iba a favorecer una concertación entre los partidos políticos "para estabilizar la democracia", ésta no podía significar "una especie de pacto de Moncloa", en referencia al acuerdo que en España, tras el fin de la dictadura de Francisco Franco, había dispuesto "una especie de gran tregua, para que los poderosos siguieran haciendo pagar los resultados de la crisis a las masas del pueblo". Consolidar la democracia, para Arismendi, no era sinónimo de gobernabilidad. ${ }^{41}$

Otra desviación puede encontrarse en la propuesta de una "democracia participativa", realizada por el dirigente wilsonista Juan Raúl Ferreira, quien en noviembre de 1984 reivindicó el fomento de la movilización y la participación del ciudadano en la política que había distinguido al gobierno del panameño Omar Torrijos. ${ }^{42}$

\section{La democracia sin política}

Un balance de los cinco años de democracia realizado por el Centro Uruguay Independiente (CUI) en 1989 puso sobre la mesa la relación entre la política y los jóvenes, remarcando que para ellos "todos los políticos [eran] iguales" e igualmente desconfiables. La derrota en el Plebiscito por la derogación de la Ley de Caducidad, en abril del 1989, "generó un gran sentimiento de frustración especialmente en las generaciones más jóvenes". Sumada a una realidad social y económica "que [los] expulsa y que no les brinda las mínimas oportunidades de realización", esto arrojaba una extrema frialdad con respecto a la política. ${ }^{43}$

nas reflexiones sobre los resultados electorales de 1984", en Uruguay, partidos políticos y sistema electoral, Montevideo, El Libro Libre / FUCCYT, 1988); Juan Rial (Uruguay: elecciones de 1984. Un triunfo del centro, Montevideo, Ediciones de la Banda Oriental, 1985; "Hacia el autoritarismo. 1968-73 (Mayo/84)" y "Los partidos políticos: ¿restauración o renovación? (abril 1984)", en: Partidos políticos, democracia y autoritarismo, Tomo II Montevideo, Centro de Informaciones y Estudios del Uruguay / Ediciones de la Banda Oriental, 1984); Carlos Zubillaga y Romeo Pérez (La democracia atacada, Montevideo, Ediciones de la Banda Orietal, 1988). La politóloga argentina Cecilia Lesgart ha analizado el clima intelectual en el que surgió la idea de "transición a la democracia", cuya presencia es muy fuerte en varios de estos trabajos (Usos de la transición a la democracia: ensayo, ciencia y política en la década del ochenta, Rosario, Homo Sapiens, 2003). Carlos Demasi ha analizado la influencia del clima "concertador", propio de la segunda mitad de la década de los ochenta, en las construcciones de las Ciencias Sociales, particularmente en el citado trabajo de Caetano, Rilla y Pérez ("La partidocracia uruguaya. Aportes para la discusión de una hipótesis", en Contemporánea, año 3, vol. 2, Montevideo, Universidad de la República, 2012).

39 "Reportajes sin corbata. Jorge Luis Batlle", en Guambia. Expresión uruguaya de humor, año I, n 15, [enero-febrero] de 1984, p. 36.

40 Ver: Mauricio Bruno, "Contra el consenso político y por la racionalidad económica. El semanario Búsqueda de cara a las elecciones de 1984", en Álvaro De Giori, Carlos Demasi (comps.), El retorno a la democracia. Otras miradas, Montevideo, Fin de Siglo, 2016.

41 Rodney Arismendi, "Vísperas combativas de la derrota de la dictadura", en Estudios, n 91, juli 1984, p. 4; "Consolidar la democracia, avanzar en democracia en la perspectiva de un gobierno popular. Tres preguntas a Rodney Arismedi", en Estudios, n 95, diciembre de 1985, pp. 5-6, citado por: Marisa Battegazzore, "El concepto de 'Democracia Avanzada' en Rodney Arismendi: un referente el proceso político latinoamericano". Disponible on line en: http://www.quehacer.com.uy/index.php?option=com_content\&view=article\&id=300:democracia-avanzada\&catid=94:rodney\&ltemid=77 Acceso: 16 de diciembre de 2013.

42 Entrevista a Juan Raúl Ferreira, en La Democracia, $1^{\circ}$ de noviembre de 1984. Esta exhortación fue duramente contestada por el batllista Enrique Tarigo, quien concebía al uruguayo medio de la misma forma en que lo hiciera Benedetti más de veinte años antes, aunque cambiando la connotación negativa por la positiva. Para Tarigo "esos manipuleos de la gente" eran muy peligrosos: "el vívere pericolosamente no es el modo de vida que ambicionamos, que hemos de lograr y que nos merecemos los uruguayos. [...] no estamos dispuestos [...] a sustituir el aventurerismo militar por el aventurerismo civil". (Editorial de Enrique Tarigo en Opinar, 10 de noviembre de 1984, Citado en: Marcelo Pereira, op. cit., pp. 221-222).

43 Marcos Gutiérrez, María Inés Moraes, Fernando Pita, Uruguay 1985-1989. Impulso democrático bloqueo conservador, Montevideo, Centro Uruguay Independiente, 1989. 
En este contexto, no es extraño que también la democracia estuviera fuertemente desprestigiada entre algunos sectores juveniles. Claro que no entre todos, pero sí entre un sector emergente muy visible, fundamentalmente montevideano, cuyo núcleo estaba hecho de adolescentes durante la etapa final de la dictadura, que se caracterizó por una fuerte intervención en el espacio público no desde intereses ideológicos sino, a decir del filósofo Ruben Tani, "estético-culturales", canalizados en medios como el Rock and Roll, la formas de expresión artística alternativa (el grafitti, la performance), la poesía y las revistas "subterráneas". 44

El documental Mamá era punk, dirigido por Guillermo Casanova y realizado en 1988, ofrece un panorama desde adentro de esta generación, caracterizado por referencias negativas al Uruguay y a la democracia. El guitarrista y cantante de ADN Juan Berhau, sintetizaría esta posición durante una entrevista, al querer explicar el carácter colectivo y horizontal de la composición musical en la banda y no poder encontrar la palabra justa: "la cosa es, no quiero decir democrática, porque la palabra está en decadencia, pero el trabajo de creación es entre todos". 45

En julio de 1989 la Oficina Nacional de Servicio Civil de la Presidencia organizó un seminario internacional en torno a uno de los temas de mayor actualidad política: el rol del Estado en una sociedad democrática. Reunidos en una de las salas de exposiciones del Palacio Municipal, diversos especialistas internacionales en el área de la gestión pública presentaron estudios de caso y diagnósticos acerca del estado de la cuestión en los países de Latinoamérica y el Caribe. Sobre el final de la jornada, luego de finalizadas las exposiciones de los expertos, vino el turno de los políticos. Cerrando la oratoria, Jorge Batlle dio un panorama de la situación uruguaya en el contexto internacional y, al mismo tiempo, fijo un uso del concepto de democracia que no era novedoso, pero que ganaba terreno en la clase política uruguaya y que adelantaba rasgos del sentido común dominante durante los años siguientes.

Para Batlle, si los uruguayos querían mantener y afirmar "el deseo común de todos de ser demócratas" y si además de a "sobrevivir manteniendo su nivel de vida" aspiraban a "crecer, transformarse, ser más libres", había un hecho incontrastable que tenían que aceptar: "en los próximos diez años, en forma casi definitiva, el mundo se globalizará en grandes áreas [...] globalizando la tecnología, globalizando el mercado, globalizando las comunicaciones, globalizando la competencia".

Uruguay debía "reconocer esa realidad y aceptar ese desafío", sumarse a esa corriente porque, de no hacerlo, "el mundo, no va a esperar por nosotros, no se va a detener por nosotros, nos va a dejar de lado si nosotros rechazamos la realidad en la cual el mundo vive y se dispone a vivir". La realidad estaba hablando y era clara y contundente, "porque ella puede más que nuestra ensoñación, que nuestras aspiraciones de utopías y de ideales". De no oírla, "por más que tengamos racional y emocionalmente, el deseo de mantenernos demócratas, eso no pasará de una mera expresión retórica" ${ }^{46}$

Si la democracia de Sanguinetti había sublimado las formas políticas del liberalismo, la de Batlle daba un paso más y hacía lo mismo con las económicas: para Batlle, la democracia era un espejo del mercado. Ser demócrata equivalía a sostener una posición privilegiada en el juego de los intercambios. Por eso, si el Uruguay no lograba subirse al carro de la globalización, de nada serviría "decirse demócrata". Eso no pasaría de mera retórica, de un palabrerío vacío incompatible con la realidad de un país atrasado, incapaz de proporcionar un "nivel de vida" adecuado a sus habitantes. Más que derechos, la democracia debía garantizar cierto estándar de vida, una vida en "plenitud".

De alguna manera, Batlle postulaba una democracia sin política, una traslación mecánica al campo político de lo que los neoliberales calificaban como el "normal funcionamiento de la economía". No se ha investigado aún el progresivo avance del lenguaje neoliberal en el campo político uruguayo hacia la segunda mitad de la década de 1980, pero cabe señalar que

44 "La movida de los 80: la ruptura cultura en el Uruguay (I)", en Henciclopedia, versión on line en http://www.henciclopedia.org.uy/autores/ Verdesio/Movida80.htm [Acceso: 23 de diciembre de 2013].

45 Mamá era punk, Dir. Guillermo Casanova, Montevideo, CEMA, 1988 [Disponible on line en: http://www.youtube.com/watch?v=l822azAOcXg. Acceso: 13/12/2013]; "Gas de combate. Cadáveres ilustres", Gas. Generación ausente y solitaria, n² 2, s.f [1987], pp. 11-12; "'Suiza de América' a los Traidores (Montevideo Agoniza)", Gas. Generación ausente y solitaria, n³, setiembre de 1987, p. 7; "Gas de combate. ADN", Gas. Generación ausente y solitaria, $\mathrm{n}^{\circ} 3$, setiembre de 1987, pp. 8-9.

46 Ruben Correa Freitas, Rolando Franco (comp.), Gestión del Estado y desburocratización, Montevideo, El Libro Libre, 1989, pp. $273-274,289$. 
esa lógica economicista se reflejó antes en una suerte de colonización del lenguaje político por parte del económico. En diciembre de 1984 la revista Crónicas Económicas publicó un reportaje a Roberto Ceruzzi, director de Agencia Corporación Publicitaria, el "cerebro" tras la campaña electoral de Sanguinetti. La revista iba al grano al arrojar los resultados del "estudio de mercado" realizado por la agencia. Para Ceruzzi, la ciudadanía uruguaya era "un mercado con avidez de consumir un producto que se llamaba 'democracia"', y a ese producto se lo veía "como un medio para obtener cosas tangibles y no tanto como un fin". Para "la gente", la democracia era "un medio para obtener mejoras salariales, niveles de ocupación, tener un mejor nivel de vida, etc. Luego surgían los problemas de las pasividades, la vivienda, la salud" y, en tercer lugar, "con muy poco interés de mercado", venían "las libertades individuales, el poder judicial independiente, las desproscripciones, etc." .47

\section{Conclusiones}

Pensar la historia reciente del Uruguay desde la perspectivas de los usos y sentidos del lenguaje permite enriquecer las discusiones acerca de cómo pensaban y cuáles eran los objetivos de los actores políticos que protagonizaron los conflictos marcados por la Guerra Fría. Un análisis contextual de los conceptos, que los relacione con la pertenencia política e ideológica de quienes los emplearon, con los debates de los que formaron parte y sobre todo con los conceptos que se utilizaron para definirlos por cercanía u oposición, permite escapar a la tentación de adjudicarles sentidos unívocos y anacrónicos.

El periplo de la democracia uruguaya durante, aproximadamente, fines de la década del cincuenta y fines de los años ochenta del siglo XX está en el centro de muchos debates sobre la historia reciente del Uruguay. Pero no siempre los abordajes que se realizan en esta línea se preocupan por pensar qué entendían por democracia aquellos actores que la impugnaron o que la defendieron. Examinar de forma panorámica ese período a la luz de esta pregunta ha sido el objetivo de este trabajo.

En esos años, en Uruguay hubo una fuerte disputa por el sentido del concepto de democracia. Como diría el ex dirigente frenteamplista Juan Pablo Terra en 1990, se trataba de una palabra "con tal capacidad de despertar resonancias en la conciencia de la gente, que nadie quiere entregarla a su adversario." ${ }^{48}$ Esta disputa dio lugar a una pluralidad de sentidos, que atravesaron los campos político y cultural y que expresaron diversas ideas no solo en torno cómo debía conformarse y ejercerse el gobierno y que espacios de la vida social debían estar o no sujetos a su influencia, sino también a quiénes y cómo eran los uruguayos y cuáles debían ser sus proyectos a futuro como sociedad. Por otro lado, estas diversas acepciones de la democracia funcionaron como armas políticas. Su construcción en uno u otro sentido expresó, más que puntos de vista en torno a debates teóricos o científicos, posturas políticas forjadas en función de las discusiones de cada momento.

Durante la década de 1960, a caballo de la crisis económica, social y política que se extendió en el país, la impugnación que la izquierda hizo de la realidad uruguaya se apoyó con fuerza en la crítica a un imaginario democrático que permitía la autosatisfacción nacional y que impedía ver, a su juicio, la profundidad de la crisis. Las derecha antiliberales, cuyo crecimiento e importancia en el espectro político también se verificó durante esos años, usaron el concepto para aglutinar ideas esencialistas sobre la nación y lo despojaron de sus contenidos garantistas; durante la dictadura civil militar, este sentido de la democracia se afirmó y funcionó como base para pensar la construcción de nuevas instituciones, que deberían ocupar el lugar de las derruidas instituciones republicanas. A comienzos de los años ochenta, el concepto de democracia tuvo una pluralidad de usos y sentidos. Por un lado, sirvió para que el amplio arco opositor a la dictadura hilvanara sus fuerzas en un solo haz y potenciara sus reivindicaciones; por otro, para que rápidamente las élites de los partidos políticos crearan un relato en el que pasaban a ser conductoras hegemónicas del proceso y desplazaran a otros actores; además, para que algunos sectores políticos que tenían una importante capacidad de movilización popular —el sector wilsonista del Partido

47 Reportaje a Roberto Ceruzzi, Crónicas Económicas, n 178, diciembre de 1984. Citado en: Marcelo Pereira, op. cit., p. 247. Otro ejemplo de cómo las metáforas acerca del funcionamiento de la economía comenzaron operar como un lenguaje capaz de ofrecer sentido acerca la política puede verse en el semanario Búsqueda, que en noviembre de 1984 calificaba a la legitimidad constitucional "como un capital" que debía ser administrado "con parsimonia, con esmero, con cariño", porque si no "se pierde, como la fortuna del pródigo" ("El proceso ha muerto, ¡Viva la República!", en Búsqueda, 21 de noviembre de 1984, p. 2).

48 Juan Pablo Terra, La conversión de un gigante. La crisis de la URSS y su impacto en la izquierda latinoamericana, Montevideo, Ediciones de la Banda Oriental, 1990, p. 86. 
Nacional hacia 1984, el Partido Comunista- y que discrepaban con esa visión, reclamaran un mayor control "popular" de las decisiones de las élites; o bien para que actores económicos con fuerte capacidad de agencia trataran de imponer una visión en la cual la política dejaba de tener la iniciativa sobre la economía. Sin mencionar las acepciones que surgieron desde el campo de las Ciencias Sociales, que influyeron y a su vez fueron influidas por las discusiones del campo político.

Todos ellos reivindicaron a la democracia, pero algunas de sus concepciones tuvieron más suerte que otras y eso dependió más de factores políticos que de una interpretación correcta de algún sentido natural de la palabra. Este trabajo buscó mapear estas concepciones, historizarlas y relacionarlas entre sí, durante un período extenso e intenso, en el cual el lenguaje político produjo muchas novedades. Cabe, por supuesto, la necesidad de realizar abordajes más profundos y específicos, que ahonden en esos diversos usos y sentidos de la democracia, así como de otros conceptos clave para entender el Uruguay de los últimos sesenta años. 


\section{Resumen}

Este trabajo intenta a una aproximación a los usos y sentidos del concepto de democracia en el Uruguay, entre 1958 y 1989. Mediante un abordaje panorámico, identifica discursos y prácticas que circularon en los campos político y cultural y que se disputaron el sentido de la democracia. En esta línea, más que trazar una definición precisa del concepto y analizar el comportamiento de los actores a luz de ella, el trabajo identifica cuáles fueron las definiciones que los actores asumieron como propias, los factores políticos y sociales que incidieron en esas construcciones, la forma en que esas construcciones se relacionaron entre sí y los derroteros que siguieron a lo largo del período.

\section{Palabras clave}

Democracia; Uruguay; Historia reciente

\section{Abstract}

This paper attempts to approximate the uses and meanings of the concept of democracy in Uruguay between 1958 and 1989. Through a panoramic approach, it identifies discourses and practices that circulated in the political and cultural fields and that disputed the sense of democracy. In this line, rather than drawing a precise definition of the concept and analyzing the behavior of the actors in light of it, the work identifies what were the definitions that the actors assumed as their own, the political and social factors that influenced these constructions, the how these constructions were related to each other and the paths that followed throughout the period.

\section{Keywords}

Democracy; Uruguay; Recent history 